\title{
Bilateral Simultaneous Ureteroscopic (BS-URS) Approach in the Management of Bilateral Urolithiasis Is a Safe and Effective Strategy in the Contemporary Era-Evidence from a Systematic Review
}

\author{
Robert M. Geraghty ${ }^{1} \cdot$ Bhavan P. Rai $^{2} \cdot$ Patrick Jones $^{3} \cdot$ Bhaskar K. Somani $^{1}$
}

Published online: 17 February 2017

(C) The Author(s) 2017. This article is published with open access at Springerlink.com

\begin{abstract}
Purpose of Review Ureteroscopic treatment of urolithiasis has become safer and more effective in the modern era. With a rise in the incidence of bilateral urolithiasis, management dilemma of staged single-side ureteroscopy versus bilateral simultaneous ureteroscopy (BS-URS) is often debatable. This review evaluates the current evidence base for bilateral simultaneous ureteroscopic approach in the modern era.

Recent Findings A systematic review was conducted from 1990 to June 2016 including all English language articles reporting on outcomes of BS-URS for urolithiasis. Data was split into two periods: period 1: 2003-2012 and period 2: 2013-2016, and analysed using SPSS version 21. A total of 11 studies (491 patients) were identified from a literature search of 148 studies with mean age of 45 years and a male: female ratio of 2:1 and a mean operative time of $69 \mathrm{~min}$ $(\mathrm{SD}= \pm 15)$. The initial and final stone-free rate (SFR) was 87 and $93 \%$, respectively. Post-operative stents were placed in $89 \%$ of patients with a mean hospital stay of 1.6 days $(\mathrm{SD}= \pm 0.5)$. Overall, there was a significant negative association between case volume (procedures per month) and complication rate $(p=0.045)$. Mean hospital stay was significantly longer in period $1(1.9$ days, $\mathrm{SD}= \pm 0.5)$ than period 2 (1.3 days, $\mathrm{SD}= \pm 0.3)$ and complications were also significantly higher in period $1(47 \%)$ compared to period $2(12 \%)$
\end{abstract}

This article is part of the Topical Collection on Kidney Diseases

Bhaskar K. Somani

bhaskarsomani@yahoo.com

1 Department of Urology, University Hospital Southampton NHS Trust, Southampton SO16 6YD, UK

2 James Cook University Hospital, Middlesbrough, UK

3 Blackpool Teaching Hospital NHS Trust, Blackpool, UK $(p<0.001)$. There were six studies examining holmium laser (HL) lithotripsy and three examining pneumatic lithotripsy (PL). There were significantly more complications after PL than HL; however, their SFR was similar.

Summary Our review shows that the complication rates and hospital stay are significantly reduced in the contemporary data suggesting an improving trend in outcomes following BS-URS. Simultaneous bilateral ureteroscopic treatment of urolithiasis is safe and effective in the modern era. Safety is increased in centers with increased number of procedures performed and with laser lithotripsy.

Keywords Bilateral $\cdot$ Calculi $\cdot$ Laser $\cdot$ Review $\cdot$ Simultaneous

\section{Introduction}

The evolution of sophisticated miniature ureteroscopes and holmium laser technology has significantly reduced morbidity associated with ureteroscopy (URS). Evidence from contemporary literature suggests complications between 2.4 and $8.6 \%$ with URS $[1,2]$. Ureteroscopy is increasing becoming the approach of choice in complex endourological management [2-4, 5•]. Despite this, the management of bilateral urolithiasis is a subject of much contention and debate amongst endourologists worldwide. Staged single-side URS is often employed in preference to a bilateral simultaneous ureteroscopic (BS-URS) approach. The concerns over BS-URS are due to higher morbidity in comparison with a staged approach. However the potential benefits of BS-URS include single anesthetic session and potentially reduced cost associated with treatment. In an era of austerity these are important considerations while making surgical decisions [6-8]. A recent systematic review of seven studies evaluating BS-URS did report an overall stone-free rate (SFR) of $90 \%$ suggesting it was a feasible strategy. However, 
they did report an overall complication rate of nearly $50 \%$, although majority of them were Clavien score $\leq$ II [9]. In this updated review, we aim to evaluate the following:

(1) Feasibility, effectiveness and safety of BS-URS approach

(2) Outcomes of bilateral simultaneous ureteroscopic BSURS approach in a contemporary era

(3) Factors that predict complications of BS-URS approach

\section{Methods and Materials}

\section{Evidence Acquisition: Criteria for Considering Studies for This Review}

Inclusion criteria:

(1) All articles written in the English language

(2) Studies reporting on outcomes following BS-URS for urolithiasis

(3) Patients of any age

Exclusion criteria:

(1) Studies reporting on outcomes of BS-URS for nonurolithiasis indication such as malignancy

(2) Studies with $<10$ patients

\section{Search Strategy and Study Selection}

The systematic review was performed according to the Cochrane Review and the preferred reporting items for systematic reviews and meta-analyses (PRISMA) guidelines. The search strategy was conducted to find relevant studies from Ovid Medline without revisions (1996-July 2016), Cochrane Library (2016), CINAHL (1990-July 2016), Clinicaltrials.gov, Google Scholar and individual urologic journals.

Terms used included 'bilateral', 'simultaneous', 'synchronous', 'ureteroscopy', 'ureterorenoscopy', 'calculi', 'stones' and 'urolithiasis'. Boolean operators (AND, OR) were used to refine the search.

The search was limited to English language articles between 1996 and July 2016. Authors of the included studies were contacted in the case of data not being available or clear. Level of evidence was assessed using the recommendations set out by the Centre for Evidence-Based Medicine [10].

Two reviewers (RG and BS) independently identified all studies that appeared to fit the inclusion criteria [11-21] (see Fig. 1).

\section{Data Extraction and Analysis}

The following variables were extracted from each study: year of publication, study period, number of patients/ renal units included, operative time, initial and final SFR, lithotripsy fragmentation device, post-operative stent use, stone size $(\mathrm{mm})$, cumulative stone diameter (CSD) $(\mathrm{mm})$ and complications. Complications were graded using the Clavien Dindo classification [9] in all studies. Case volume was calculated as procedures per month during the study period as reported in the individual studies. For subanalysis, the data was divided into historical and contemporary studies by splitting the collated data into Period 1 (2003 to 2012 inclusive) and Period 2 (2013 to July 2016 inclusive) [22••].

Data was collated using Microsoft Excel (version 12.2.4) and analyzed using SPSS (version 21). Chi square test was used for dichotomous data and independent $T$ test for continuous data.

\section{Outcome Measures}

Primary outcomes:

1) Operative time;

2) Proportion of patient requiring insertion of ureteric stent

3) Stone-free rates (SFRs)

4) Hospital stay

5) Complication Rates

Secondary outcomes:

1) Compare outcomes between studies 2003-2012 (period 1) $[22 \bullet \bullet]$ vs. $2013-2016($ period 2$)$

2) Evaluate predictors of complications.

\section{Results}

\section{Literature Search and Included Studies}

Our literature search produced 148 titles of which 131 articles were excluded due to non-relevance based on the title and abstract (see Fig. 1). Six further papers were excluded upon reading the full manuscript leaving 11 papers, which were included in the study [11-21]. Most studies were retrospective in nature and were no randomization or control groups in these studies (see Table 1). All studies reported on BS-URS and associated variables mentioned in the data extraction section.

The type of ureteroscope used varied in these studies. Five studies used semirigid ureteroscopes only [12-15, 
Fig. 1 PRISMA flow diagram for article selection process
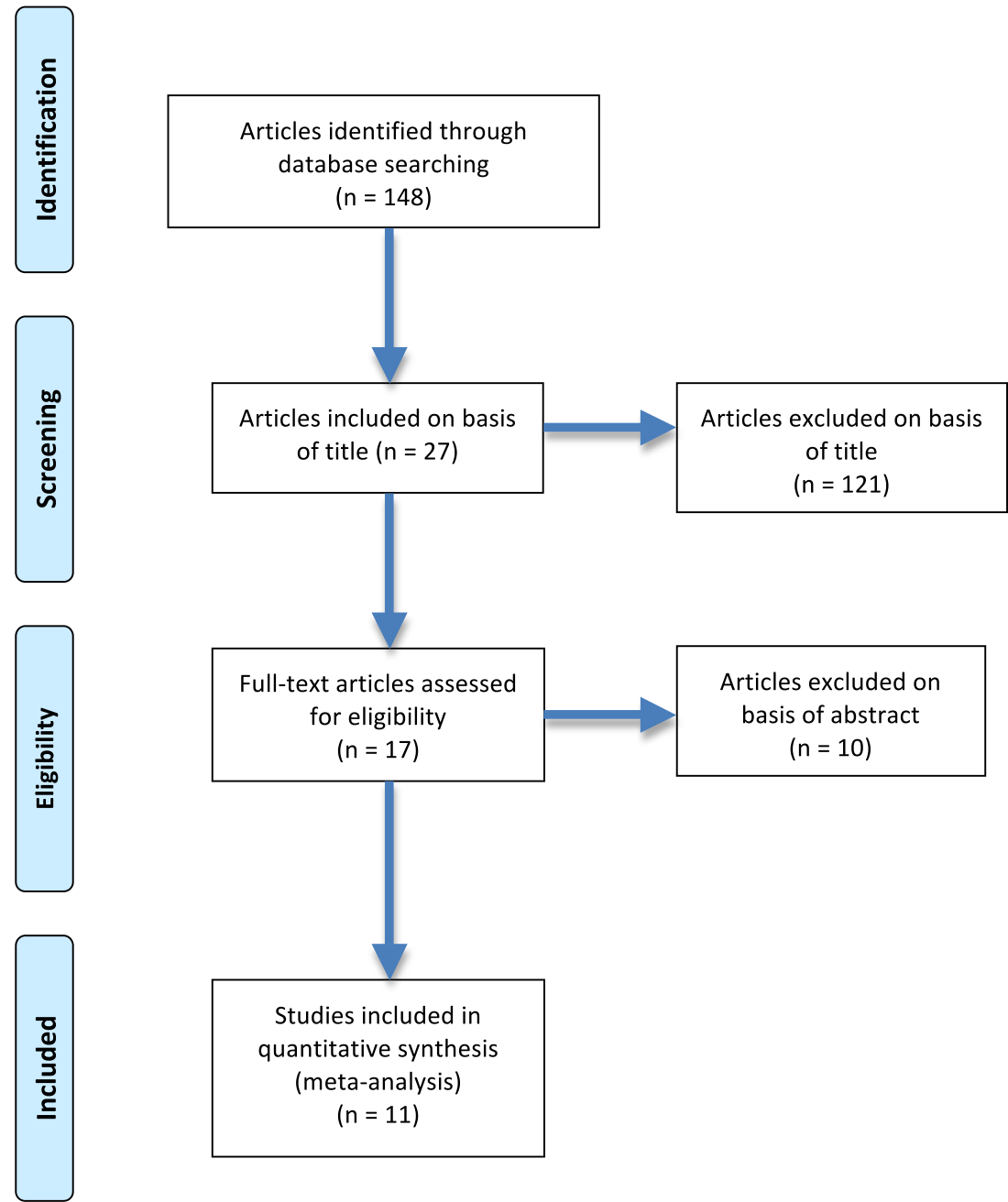

17], two studies used flexible ureteroscopes only [16, 19] and the other four studies used a combination of semirigid and flexible ureteroscopes $[11,18,20]$. (see Table 1).

Table 1 Study characteristics

\begin{tabular}{|c|c|c|c|}
\hline Study & Type & LOE & URS \\
\hline Hollenbeck, 2003 [11] & Unclear & 3 & Semi $(6.9 F) / F l e x i ~(7.5 F)+H L$ \\
\hline Darabi, 2005 [12] & Unclear & 3 & $\begin{array}{l}\text { Semirigid (unclear) + lithotripsy ND ( } 8 \mathrm{~F} \text { Wolf } \\
\quad \text { or } 10.5 \mathrm{~F} \mathrm{Storz})\end{array}$ \\
\hline El-Hefnawy, 2011 [13] & Retrospective & 3 & Semirigid + PL + HL (8F/10F Wolf) \\
\hline Mushtaque, 2012 [14] & Unclear & 3 & Semirigid + PL (7.8F) \\
\hline Gunlusoy, 2012 [15] & Unclear & 3 & Semirigid $(8 F / 10 F)+P L$ \\
\hline Huang, 2012 [16] & Retrospective & 3 & Flexi + HL (URF-P5 Olympus) \\
\hline Isen, 2012 [17] & Unclear & 3 & Semirigid + PL (8F/9.8F Wolf) \\
\hline Atis, 2013 [18] & Retrospective & 3 & Semi/Flexi + HL \\
\hline Alkan, 2014 [19] & Retrospective & 3 & Flexi + HL (URF-P5 Olympus/Wolf) \\
\hline Drake, 2015 [20] & Retrospective & 3 & Semirigid (6.5 F)/Flexi (Storz) + HL \\
\hline Bansal, 2016 [21] & Retrospective & 3 & Flexi + HL \\
\hline
\end{tabular}

$L O E$ level of evidence, $H L$ holmium lithotripsy, $P L$ pneumatic lithotripsy, Flexi flexible ureteroscope 
Table 2 Patient and stone demographics

\begin{tabular}{lllll}
\hline Study & Patients, $n$ & M:F & $\begin{array}{c}\text { Mean age, years } \\
\text { (SD/range) }\end{array}$ & $\begin{array}{l}\text { Mean cumulative stone diameter, } \\
\text { mm (SD/range) }\end{array}$ \\
\hline Hollenbeck, 2003 [11] & 23 & ND & $52( \pm 14.9)$ & $16.1( \pm 11.7)$ \\
Darabi, 2005 [12] & 19 & $10: 13$ & ND (4-78) & ND \\
El-Hefnawy, 2011 [13] & 89 & $68: 21$ & $49(13-74)$ & ND \\
Mushtaque, 2012 [14] & 60 & $38: 22$ & ND $(11-60)$ & ND $(5-20)$ \\
Gunlusoy, 2012 [15] & 55 & $37: 18$ & $46.1(22-81)$ & $10.7( \pm 4.2,5-21)$ \\
Huang, 2012 [16] & 25 & $13: 12$ & $49.8(28-69)$ & $24( \pm 5,17-37)$ \\
Isen, 2012 [17] & 41 & $17: 24$ & $41.2(28-76)$ & $8.8(7-16)$ \\
Atis, 2013 [18] & 42 & $28: 14$ & $39.2( \pm 14.2)$ & $24.09( \pm 6.37)$ \\
Alkan, 2014 [19] & 42 & $28: 14$ & $40.1( \pm 10.8)$ & $30.0( \pm 15.4,10-85)$ \\
Drake, 2015 [20] & 21 & $8: 13$ & $46(22-76)$ & $21(4-63)$ \\
Bansal, 2016 [21] & 74 & $50: 24$ & $39.2( \pm 15.2)$ & $11.7( \pm 2.4)$ \\
\hline
\end{tabular}

$S D$ standard deviation, $N D$ not documented a moderate male preponderance $(2: 1)$. The overall mean age was 44.7 years ( $\mathrm{SD}= \pm 4.7$ years). Stone size was reported in all but one study [12]. Mean stone size across these studies was $15.3 \mathrm{~mm}(\mathrm{SD}= \pm 6.5 \mathrm{~mm})$ (see Table 2).

Overall six studies [11, 16, 18-21] treated bilateral renal stones, three studies treated renal stones with contralateral ureteric stones $[11,19,20]$ and eight studies $[11-15,17,19$, 20] treated bilateral ureteric stones (see Tables 3 and 4).

\section{Definition of Stone-Free Status}

There was variation in how 'stone free' status was defined amongst included studies. Four studies defined it as fragments $<4 \mathrm{~mm}$ [17-19, 21]. Drake et al. [20], Huang et al. [16] and Gunlusoy et al. [15] defined stone free $\leq 2 \mathrm{~mm},<1 \mathrm{~mm}$ and no stones, respectively. The rest did not specify how stone-free status was defined (see Table 5). Imaging modality and the time duration between intervention and imaging is also demonstrated in Table 5.

\section{Post-Operative Characteristics and Patient Outcomes}

(1) Operative time:

Overall mean operative time was $68.7 \mathrm{~min}$ $(\mathrm{SD}= \pm 15.2 \mathrm{~min})$, although two studies did not report operative times $[12,13]$.

(2) Proportion of patient requiring insertion of ureteric stent Reporting on post-operative stent insertion was variable. Ten studies reported on post-operative ureteric stent insertion, and of those only two studies reported whether they were inserted bilaterally or unilaterally $[18,20]$. The study by Darabi et al. [12] was unclear on their results on stent insertion (see Table 4). The overall stent insertion was $88.8 \%$. Of the two studies that reported on bilateral stent insertion the overall bilateral stent insertion rate was $71.6 \%$.
Table 3 Distribution of stones treated and stone-free rates (SFRs) of bilateral ureteric and renal stones

\begin{tabular}{llllll}
\hline Study & Renal only, $n$ & $\begin{array}{l}\text { Renal/ureteric, } \\
n\end{array}$ & $\begin{array}{l}\text { Ureteric } \\
\text { only, } n\end{array}$ & $\begin{array}{l}\text { Ureteric } \\
\text { SFR (\%) }\end{array}$ & Renal SFR (\%) \\
\hline Hollenbeck, 2003 [11] & 15 & 4 & 4 & 100 & 63 \\
Darabi, 2005 [12] & - & - & 38 & 84.2 & ND \\
El-Hefnawy, 2011 [13] & - & - & 178 & 95.5 & ND \\
Mushtaque, 2012 [14] & - & - & 120 & 85 & ND \\
Gunlusoy, 2012 [15] & - & - & 110 & 94.5 & ND \\
Huang, 2012 [16] & 128 & - & - & ND & 88.5 \\
Isen, 2012 [17] & - & - & 82 & 98.7 & ND \\
Atis, 2013 [18] & 84 & - & - & ND & 97.6 \\
Alkan, 2014 [19] & 47 & 37 & 4 & ND & ND \\
Drake, 2015 [20] & 12 & 11 & 2 & 100 & 75 \\
Bansal, 2016 [21] & 148 & - & - & ND & ND \\
Total & 434 & 52 & 538 & 94.0 & 81.0 \\
\hline
\end{tabular}

$N D$ Not documented, $n$ number of patients 
Table 4 Operative demographics

\begin{tabular}{lll}
\hline Study & Op time, min (SD/range) & Stent insertion, $n(\%)$ \\
\hline Hollenbeck, 2003 [11] & $90 \pm 46$ & $18(75)$ \\
Darabi, 2005 [12] & $\mathrm{ND}$ & Unclear \\
El-Hefnawy, 2011 [13] & $\mathrm{ND}$ & $78(87.6)$ \\
Mushtaque, 2012 [14] & $40-120$ & $39(65)$ \\
Gunlusoy, 2012 [15] & $59 \pm 21(21-100)$ & $96 / 110$ units $(87.3)$ \\
Huang, 2012 [16] & $81.2 \pm 25(42-137)$ & $25(100)$ \\
Isen, 2012 [17] & $58.4(36-81)$ & $41(100)$ \\
Atis, 2013 [18] & $51.08( \pm 15.22)$ & $42(71.4 \%$ - bilateral, 28.6\%-unilateral) \\
Alkan, 2014 [19] & $89.1( \pm 35.7)$ & $36(85.7)$ \\
Drake, 2015 [20] & $70(35-129)$ & $25(100)[7$ unilateral, 18 bilateral] \\
Bansal, 2016 [21] & $51.08( \pm 15.22)$ & $65(87.83)$ \\
\hline
\end{tabular}

$N D$ not documented, $S D$ standard deviation

(3) Stone-free status (SFR)

All studies reported on SFR, with a mean initial and final SFR of 87 and $92 \%$ respectively [11-21]. The overall ureteric SFR was $94.0 \%$ and the overall renal SFR was $81.0 \%$.

(4) Hospital stay

Eight studies [13-15, 17-21] reported on hospital stay, with an overall mean hospital stay of 1.6 days $(\mathrm{SD}= \pm 0.53)$ (see Table 6).

(5) Complication rates (Table 7)

All studies reported on complications, with an overall complication rate of $25.6 \%(n=118)$. There were a total of 132 complications graded Clavien I-II and 35 complications graded Clavien $\geq$ III. One paper did not specify what the post-operative complications were [18]. One patient died as a result of a pulmonary embolus after a prolonged operation $(175 \mathrm{~min})$ in the study by Hollenbeck et al. [11].

\section{Secondary Outcomes}

(1) Comparison of historical versus contemporary studies There was no overall difference in SFR for initial and final SFR between these two time periods. Analysis of the periods 1 and 2 demonstrated a significantly longer hospital stay in period 1 (1.9 days) than in period 2 (1.3 days) ( $p=0.034,95 \% \mathrm{CI}=0.09$ to 1.60$)$. There were significantly more complications in period $1(40.5 \%)$ than period $2(11.8 \%)(p<0.001)$. Sub-analysis demonstrated significantly more Clavien I-II complications $(p<0.001)$ and Clavien $\geq$ III $(p<0.001)$ in period 1 than period 2 (see Table 7). There was just one Clavien III complication in period 2 , which was early stent removal due to stent symptoms.

(2) Predictors of complications:

Case volume: Upon regression analysis there was a significant negative association between complication

Table 5 Post-operative assessment

\begin{tabular}{llll}
\hline Study & SFR definition & Follow-up imaging to evaluate stone-free status & Time between surgery and imaging \\
\hline Hollenbeck, 2003 [11] & ND & Plain X-ray (KUB) & 1 month \\
Darabi, 2005 [12] & ND & ND & ND \\
El-Hefnawy, 2011 [13] & ND & Plain X-ray (KUB) and NCCT & After procedure and before discharge and 3 months \\
Mushtaque, 2012 [14] & Unclear & Plain X-ray (KUB) & 1 , 5 and 28 days \\
Gunlusoy, 2012 [15] & No stones & Plain X-ray (KUB), USS and IVU (in case of & 1 day and 6 weeks \\
Huang, 2012 [16] & $<1 \mathrm{~mm}$ & C & 7 days \\
Isen, 2012 [17] & $<4 \mathrm{~mm}$ & Plain X-ray (KUB) and USS or NCCT & 7 days \\
Atis, 2013 [18] & $<4 \mathrm{~mm}$ & USS and IVU & 1 day and 1 month \\
Alkan, 2014 [19] & $<4 \mathrm{~mm}$ & NCCT or USS & 3 months (stent removal at 3-4 weeks, imaging \\
& & & 2 months after) \\
Drake, 2015 [20] & $<2 \mathrm{~mm}$ & Plain X-ray (KUB) or USS & $8-12$ weeks \\
Bansal, 2016 [21] & $<4 \mathrm{~mm}$ & Plain X-ray (KUB), USS or CT & ND \\
\hline
\end{tabular}

ND not documented, NCCT non-contrast CT scan, USS ultrasound scan 
Table 6 Patient outcomes

\begin{tabular}{llll} 
Study & $\begin{array}{l}\text { Mean hospital stay, } \\
\text { days (range) }\end{array}$ & Initial (\%) & Final (\%) \\
\hline Hollenbeck, 2003 [11] & ND & ND & 88.0 \\
Darabi, 2005 [12] & ND & 84.2 & 84.2 \\
El-Hefnawy, 2011 [13] & $2.3 \pm 1(1.5-7)$ & 86.0 & 95.5 \\
Mushtaque, 2012 [14] & $2.35(1-5)$ & 85.0 & 85.0 \\
Gunlusoy, 2012 [15] & $2.4 \pm 0.9(1-5)$ & 90.0 & 94.5 \\
Huang, 2012 [16] & ND & ND & ND \\
Isen, 2012 [17] & $1.2(1-3)$ & 90.2 & 98.7 \\
Atis, 2013 [18] & $1.37( \pm 0.72)$ & 92.8 & 97.6 \\
Alkan, 2014 [19] & $1.23( \pm 0.57)$ & 86.3 & 88.6 \\
Drake, 2015 [20] & $0.9(0-7)$ & 80.0 & 92.8 \\
Bansal, 2016 [21] & $1.37( \pm 0.72)$ & 87.0 & 97.3 \\
\hline
\end{tabular}

$N D$ not documented, $S F R$ stone-free rate

rate and case volume (procedures per month) $(p=0.045$, $B=-0.285, t=0.894,95 \% \mathrm{CI}=1.156$ to 75.602 ) (see Fig. 2).

Stone size: There were no other significant correlations between complication rate and stone size $(p=0.16)$.

Holmium laser vs. pneumatic lithotripsy: There were six studies [11, 16, 18-21] examining holmium laser (HL) lithotripsy and three $[14,15,17]$ examining pneumatic lithotripsy (PL). There were significantly more complications after PL than HL (54.9 vs. $16.7 \%$, $p=0.007,95 \% \mathrm{CI}=0.74$ to 75.83$)$.

\section{Discussion}

\section{Findings of Our Study}

In this updated review, a BS-URS approach achieved an overall SFR and complication rate of 92 and 26\%, respectively. The mean hospital stay was just under 2 days. Notably, hospital stay and complications are significantly reduced in the contemporary data (from 2013) when compared with historical cohorts (prior to 2013) [22••] (see Fig. 3). Furthermore, the complication rates reported in this review are nearly half those reported in the systematic review by Rai et al. [22・•] This data suggest an improving trend of outcomes following BS-URS. Other factors that have significantly improved outcomes are higher case volume per surgeon and the use of holmium laser fragmentation. This is a clear reflection of evolving expertise, endoscopic laser technology and a wider variety of available technique and technology [23-30].

\section{Meaning and Weakness of the Study}

Hollenbeck et al. [11] compared staged URS with BS-URS for bilateral urolithiasis in a retrospective case series. They reported that BS-URS was aassociated with added morbidity; however, the cumulative risk with staged URS procedures (14\% per procedure) was similar to BS-URS (29\%). However, this data has to be viewed with caution owing to its historical nature. Contemporary data from this review suggests a more encouraging trend with regards to complications from BSURS. There has been a general reluctance to take up bilateral
Table 7 Complications during periods 1 and 2, period 1 vs period 2, Clavien I-II $(p<0.001)$, Clavien $\geq$ III $(p<0.001)$

\begin{tabular}{cll}
\hline Study period & Clavien I-II (\%) & Clavien $\geq$ III (\%) \\
\hline Period 1 & Haematuria not requiring blood & Ureteral perforation/laceration (4.2) \\
transfusion (10.6) & Mucosal injury (3.5) \\
& LUTS (8.7) & Stone migration (1.6) \\
& Pain requiring analgesia (8.3) & Stent symptoms requiring early \\
& Post-operative fever (4.2) & removal (0.6) \\
& UTI/urosepsis/pyelonephritis (2.9) & Urinoma (0.3) \\
& Post-obstructive diuresis (1.0) & Pulmonary embolus leading to death (0.3) \\
& Perinephric haematoma (0.3) & $10.50 \%$ \\
Total & $36 \%$ & Stent symptoms requiring early \\
Period 2 & Haematuria not requiring blood & \\
& transfusion (3.4) & \\
$2013-2016$ & Pain requiring analgesia (2.8) & \\
& Post-operative fever (2.8) & \\
& Not specified (1.1) & $1.10 \%$ \\
Total & Pyelonephritis (0.6) & \\
\hline
\end{tabular}

LUTS lower urinary tract symptoms 
Fig. 2 Graph demonstrating case volume (procedures per month) against post-operative complication rate. Significant regression, $p=0.045, B=-0.285$, $t=0.894,95 \% \mathrm{CI}=1.156$ to 75.602

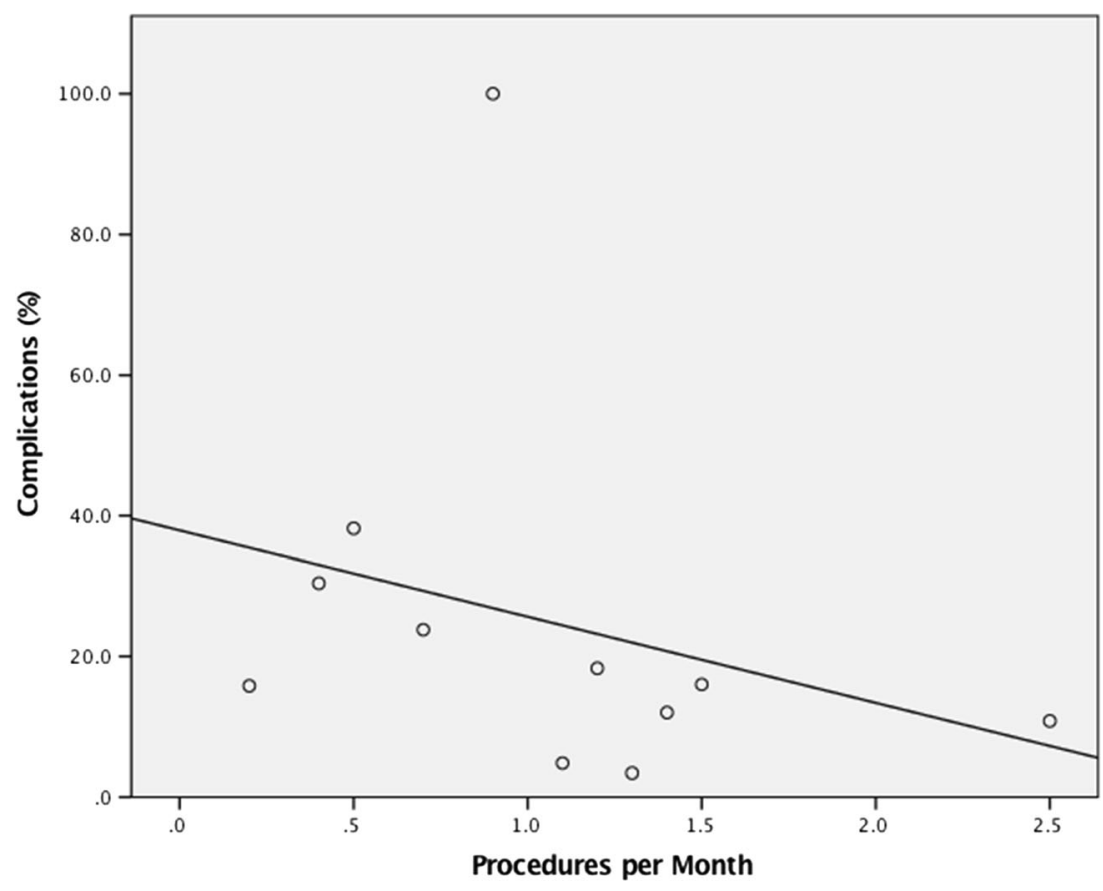

simultaneous management of urolithiasis. In a prospective study, Shen et al. [31] compared single-staged simultaneous URS and PCNL with staged procedures. They demonstrated a SFR of $92.3 \%$ with a low complication rate (11.5\%). No complications were graded higher than Clavien III. Additionally, they reported significant reductions in anaesthetic time, operative time, hospital stay and costs with a single-stage approach, thus demonstrating feasibility and potential benefits of single-session strategy. Furthermore, bilateral single- session strategy has been reported with percutaneous nephrolithotomy (PCNL) and shock wave lithotripsy (SWL). The reported SFR for PCNL and SWL when employing a bilateral single-session treatment ranged between $87-96 \%$ and 60-80\% [26-30], respectively. Whilst the SFR rates between PCNL and URS are similar, they have a demonstrably higher SFR in comparison to SWL. However, the complication rates with BS-PCNL range between 17 and 36\% [26, 27, $30]$, much higher than complication rates reported in more
Fig. 3 Graph demonstrating operative time (minutes) against stone-free rate. Significant regression, $p=0.002, B=-0.954$, $t=-7.81,95 \% \mathrm{CI}=-0.343$ to $-0.179$

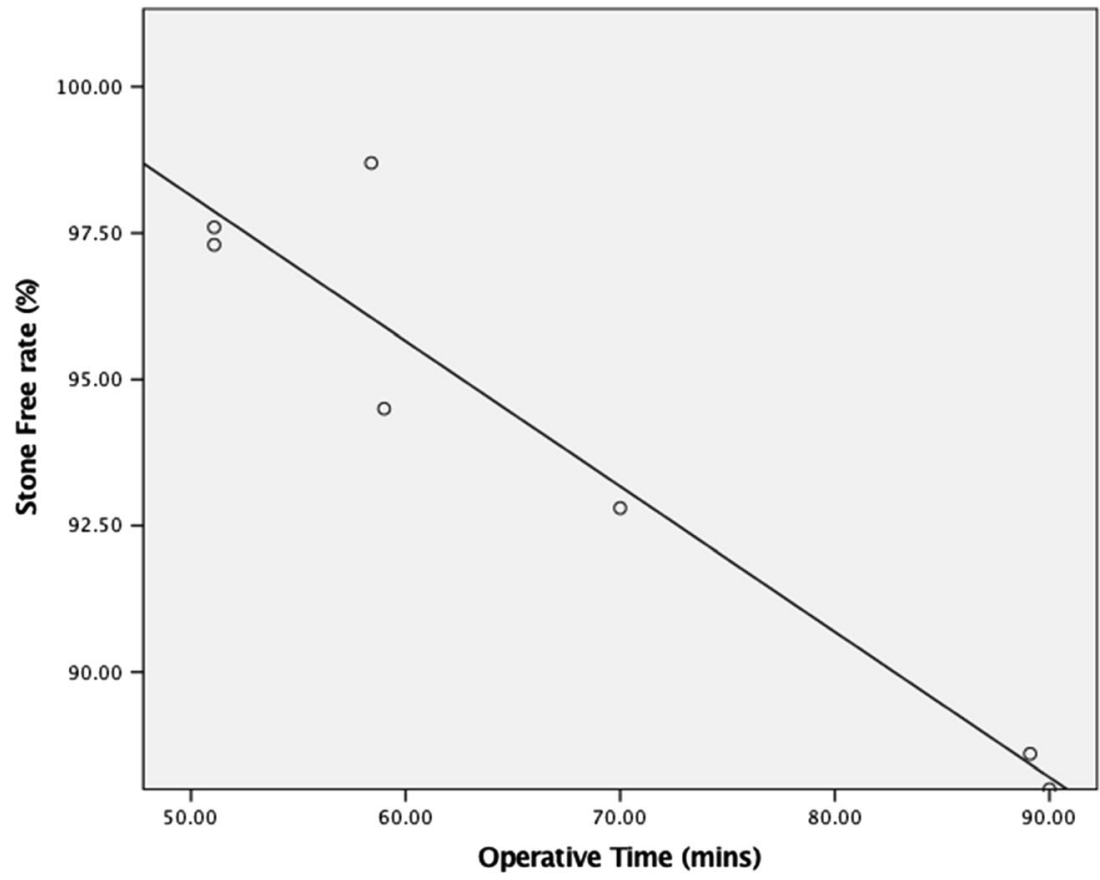


contemporary BS-URS cohorts (period 2, complication rate of $12 \%)$. BS-URS appears a more effective and safer strategy in comparison with its other counterparts.

Superior outcomes in high-volume centers and increasing caseload have been demonstrated procedures such as URS [24] and PCNL [25]. This systematic review is the first study to corroborate this observation in the context of BS-URS. This review also demonstrated that complication rates were significantly lower in studies that employed holmium laser fragmentation. These results corroborates with finding of a previous study for impacted ureteric stones, which also revealed a higher SFR with laser lithotripsy [32].

\section{Areas of Future Research}

Our review highlights the lack of high quality evidence on BSURS in the management of urolithiasis, with all studies of evidence level three. With the arrival of new digital ureteroscopes, these outcomes are likely to improve further [33]. The review raises the issue of standardization of study parameters in order to make appropriate comparisons. For example, the SFR definition varied from study to study, as did the modality of post-operative imaging and time between the intervention and imaging. Due to this lack of standardization, the authors recommend interpreting the data in this study with caution. Further prospective, multi-centred studies with standardized SFR, imaging modality and outcome parameters should be conducted in this field [34].

\section{Conclusions}

The complication rate and hospital stay for bilateral simultaneous ureteroscopy for urolithiasis are significantly reduced in contemporary studies compared to previous studies. Higher case volume and holmium laser lithotripsy are associated with fewer complications.

\section{Compliance with Ethical Standards}

Conflict of Interest Robert M. Geraghty, Bhavan P. Rai and Patrick Jones each declare no potential conflicts of interest. Bhaskar K. Somani reports honoraria from Coloplast and travel expenses covered/reimbursed by Storz.

Human and Animal Rights and Informed Consent This article does not contain any studies with human or animal subjects performed by any of the authors.

Open Access This article is distributed under the terms of the Creative Commons Attribution 4.0 International License (http:// creativecommons.org/licenses/by/4.0/), which permits unrestricted use, distribution, and reproduction in any medium, provided you give appropriate credit to the original author(s) and the source, provide a link to the Creative Commons license, and indicate if changes were made.

\section{References}

Papers of particular interest, published recently, have been highlighted as:

- Of importance

- Of major importance

1. Skolarikos A, Gross A, Krebs C, et al. Outcomes of flexible ureteroscopy for solitary renal stones in the Clinical Research Office of Endourological Society URS Global study. J Urol. 2015;194(1):137-43.

2. Geraghty R, Aboumarzouk O, Rai B, et al. Evidence for flexible ureterorenoscopy (FURS) for large renal stones in the modern era: a systematic review. Curr Urol Rep. 2015;16(8):529-35.

3. Ishii $\mathrm{H}$, Couzins $\mathrm{M}$, Aboumarzouk $\mathrm{O}$, et al. Outcomes of systematic literature review of ureteroscopy for stone disease in the obese and morbidly obese population. J Endourol. 2016;30(2):135-45.

4. Ishii H, Aboumarzouk OM, Somani BK. Current status of ureteroscopy for stone disease in pregnancy. Urolithiasis. 2014;42(1):1-7.

5. Somani BK, Giusti G, Sun Y, et al. Complications associated with ureteroscopy (URS) related to treatment of urolithiasis: The Clinical Office of Endourological Society URS Global Study. World J Urol 2016 (In Press). This paper shows large worldwide CROES data outcomes on complications associated with ureteroscopy.

6. Camilleri JC, Schwalb DM, Eshghi M. Bilateral same session ureteroscopy. J Urol. 1994;152(1):49-52.

7. Dimick JB, Pronovost PJ, Cowan JA, et al. Variation in postoperative complication rates after high-risk surgery in the United States. Surgery. 2003;134(4):534-40.

8. Katz JN, Losina E, Barrett J, et al. Association between hospital and surgeon procedure volume and outcomes of total hip replacement in the United States Medicare population. JBJS (Am). 2001;83(11): 1622-9.

9. Dindo D, Demartines N, Clavien PA. Classification of surgical complications: a new proposal with evaluation in a cohort of 6336 patients and results of a survey. Ann Surg. 2004;240:205-13.

10. OCEBM levels of evidence working group. The Oxford levels of evidence 1. Oxford Centre for Evidence-Based Medicine (2011). http://www.cebm.net/index.aspx?o=1025 (date accessed 26/7/16)

11. Hollenbeck BK, Schuster TG, Faeber GJ, et al. Safety and efficacy of same-session bilateral ureteroscopy. J Endourol. 2003;17(10): 881-5.

12. Darabi M, Keshvari M. Bilateral same-session ureteroscopy: its efficacy and safety for diagnosis and treatment. Urol J. 2005;2(1): $8-12$.

13. El-Hafnawy AS, El-Nahas AR, El-Tabey NA, et al. Bilateral samesession ureteroscopy for treatment of ureteral calculi: critical analysis of risk factors. Scand J Urol. 2011;45(2):97-101.

14. Mushtaque M, Gupta CL, Shah I, et al. Outcome of bilateral samesession ureteroscopic retrieval of stones in a single session. Urol Ann. 2012;4(3):158-61.

15. Gunlosuy B, Degirmenci T, Arslan M, et al. Is bilateral ureterorenoscopy the first choice for treatment of bilateral ureteral stones? An updated study. Urol Int. 2012;89(4):412-7.

16. Huang Z, Fu F, Zhong Z, et al. Flexible ureteroscopy and laser lithotripsy for bilateral multiple intrarenal stones: is this a valuable choice? Urol. 2012;80(4):800-4.

17. Isen K. Single-session ureteroscopic pneumatic lithotripsy for the management of bilateral ureteric stones. Int Braz J Urol. 2012;38(1):63-8. 
18. Atis G, Koyuncu H, Gurbuz C, et al. Bilateral same-session retrograde intrarenal surgery for the treatment of bilateral renal stones. Int Braz J Urol. 2013;39(3):387-92.

19. Alkan E, Avci E, Ozkanli AO, et al. Same session bilateral retrograde intrarenal surgery for upper urinary system stones: safety and efficacy. J Endourol. 2014;28(7):757-62.

20. Drake T, Ali A, Somani B. Feasibility and safety of bilateral samesession flexible ureteroscopy (FURS) for renal and ureteral stone disease. Cent European J Urol. 2015;68:193-6.

21. Bansal P, Bansal N, Sehgal A, et al. Bilateral single-session retrograde intrarenal surgery. A safe option for renal stones up to $1.5 \mathrm{~cm}$. Urol Ann. 2016;8(1):56-9.

22.• Rai BP, Ishii H, Jones P, Chapman RA, Stolzenburg JU, Somani BK. Bilateral simultaneous ureteroscopy for bilateral stone disease: a systematic review. Can J Urol. 2016;23(2):8220-6. This review showed the initial results of bilateral ureteroscopy, revealing a high risk of associated complications.

23. Zhang $\mathrm{Y}, \mathrm{Yu} \mathrm{C}-\mathrm{F}$, Jin $\mathrm{S}-\mathrm{H}$, et al. A prospective comparative study between minimally invasive percutaneous nephrolithotomy in supine position and flexible ureteroscopy in the management of single large stone in the proximal ureter. Urol. 2014;83(5):999-1002.

24. Kandasami SV, Mamoulakis C, El-Nahas AR, et al. CROES URS Global Study Group. Impact of case volume on outcomes of ureteroscopy for ureteral stones: the Clinical Research Office of the Endourological Society Ureteroscopy Global Study. Eur Urol. 2014;66(6):1046-51.

25. Opondo D, Tefekli A, Esen T, et al. CROES PCNL study group. Impact of case volumes on the outcomes of percutaneous nephrolithotomy. Eur Urol. 2012;62(6):1181-7.
26. Holman E, Khan AM, Pasztor I, et al. Simultaneous bilateral compared with unilateral percutaneous nephrolithotomy: a feasible and safe treatment. BJU Int. 2002;89(4):334-8.

27. Maheshwari PN, Andankar M, Hegde S, et al. Bilateral singlesession percutaneous nephrolithotomy: a feasible and safe treatment. J Endourol. 2000;14(3):285-7.

28. Perry KT, Smith ND, Weiser AC, et al. The efficacy and safety of synchronous bilateral extracorporeal shockwave lithotripsy. J Urol. 2000;164(3):644-7.

29. Liu CS, Zhang P, Shao ZQ, et al. Extracorporeal shockwave lithotripsy in treatment of bilateral ureteral calculi with renal colic in emergency. Nan Fang Yi Ke Da Xue Xue Bao. 2010;30(1):189-90.

30. Pillai S, Mishra D, Sharma P, et al. Tubeless simultaneous bilateral nephrolithotomy: safety, feasibility and efficacy in an Indian setting. Int J Urol. 2014;21(5):497-502.

31. Shen PF, Liu N, Wei WR, et al. Simultaneous ureteroscopic lithotripsy and contralateral percutaneous nephrolithotomy for ureteral calculi combined with renal staghorn calculi. Int J Urol. 2015;22(10):943-8. doi:10.1111/iju.12862.

32. Binbay M, Tepeler A, Singh A, et al. Evaluation of pneumatic versus holmium:YAG laser lithotripsy for impacted ureteral stones. Int Urol Nephrol. 2011;43(4):989-95.

33. Somani BK, Al-Qahtani SM, Gil de Medina SD, Traxer O. Outcomes of flexible ureterorenoscopy and laser fragmentation for renal stones: comparison between digital and conventional ureteroscope. Urology. 2013;82(5):1017-9.

34. Somani BK, Desai M, Traxer O, Lahme S. Stone-free rate (SFR): a new proposal for defining levels of SFR. Urolithiasis. 2014;42(2): 95. doi:10.1007/s00240-013-0630-3. 